\title{
Sugar sweetened beverages consumption among adolescent aged 13-15 years
}

PALLAVI PAREEK

Received: 21.04.2016; Revised: 08.05.2016; Accepted: 18.05.2016

Author for Correspondence :

\section{PALLAVI PAREEK}

Department of Home Science, Jai

Narain Vyas University, JODHPUR (RAJASTHAN) INDIA

Email : pallavibardhar@gmail.com
- ABSTRACT : A number of studies have been concluded that sugar sweetened beverage consumption has increased in all age groups. Among which nutritionally vulnerable group adolescent consumption data indicates a regular consumption. Consumption data clearly indicates a shift toward non nutritive beverages and ultimately result in poor health status of adolescents. This cross sectional study was aimed to figure out SSB consumption among adolescent aged 13-15 years. The samples were collected from private school of Jodhpur city (Rajasthan). Prevalence of SSB consumption, day wise quantity consumed in ml per day of all sugar sweetened beverages was recorded through semi structured questionnaire method. Data depicted that among all the age group 13 year aged boys consumed 79.03 per cent and 98.18 per cent girls had more soft drinks on daily basis as compared to others. All varieties of sugar sweetened beverages were also assessed according to day wise and quantity consumed. It was observed that largest number of 67.53 per cent, aged 14 year old boys consumed thrice a day and maximum of 63.65 per cent drank > 400-600 ml per day sugar sweetened beverage (SSB). While among 13 year aged, maximum number of 49.07 per cent girls consumed twice a day and higher number of 70.90 per cent had $200-400 \mathrm{ml}$ per day SSB. Statistically significant difference was observed between overall boys and girls (ml) SSB consumption ( $T$ value is 4.33 and $p<0.05$ ).

KEY WORDS: Soft drink, SSB, Adolescents, SSB consumption, SSB prevalence

- HOW TO CITE THIS PAPER : Pareek, Pallavi (2016). Sugar sweetened beverages consumption among adolescent aged 13-15 years. Asian J. Home Sci., 11 (1) : 189-194, DOI: 10.15740/HAS/AJHS/ 11.1/189-194. 